\title{
Critical Media Literacy in a Mediated Democracy
}

\section{Sayanika Dutta*}

Centre for Mass Communication and Journalism, Cotton University, Guwahati, India

\begin{abstract}
There is a crucial relationship between media, communication and democracy. They are vital to the issues of freedom and equality. In India or for that matter in any democratic country, the concept of democracy itself is constrained due to lack of informed and egalitarian discussion. The idea of a strong democracy is intrinsically linked with the idea of participation which is not a random activity but a deliberate one. Scholars have rightly argued that people should make noise, deliberate, collide, engage, share and contribute. This signifies that it is important to understand the impact of communication technologies on democracy. Media as the fourth pillar of democracy becomes central in the creation of an accessible and egalitarian public sphere. However the current media trends seem to be jeopardising the ideals of a strong democracy. Media organisations are governed by the logic of profit rather than public interest. Therefore it becomes essential for the common man to understand the patterns of ownership and control of media outlets and inquire into what is left out or marginalised. Media democratisation can only occur when people demystify the original structure, functions and operations of the media. This paper is therefore an attempt to underline the significance of critical media literacy in a mediated democracy and draw an understanding about people's perception and ideas about ownership, control, operations and functions of media.
\end{abstract}

Keywords: Media literacy; Critical media literary; Mediated democracy; Media ownership

\section{Introduction}

A vibrant democracy calls for informed and egalitarian discussion on all important issues. The idea of a strong democracy is intrinsically linked with the idea of participation which is not a random activity but a deliberate one. A democracy thrives only when its people make noise, deliberate, engage, collide, share and contribute their ideas, opinions and perspectives. One cannot deny that media offers different platforms for people to engage, deliberate and share. This holds true both for the rulers and the ruled. The relationship between media, communication and democracy is very vital. Mughan and Gunther opine that the mass communications media are the connective tissue of democracy. They are the key means through which the citizens and their elected representatives communicate and reciprocate with a view to inform and influence. One cannot ignore the fact that the media has been central to the dynamics of the relationship between the people and their representatives.

However, the expansion of the media industry and mushrooming of a number of small and big media organizations have created an unhealthy competition in the market. Media organizations are governed by the logic of profit rather than public interest. What we see or rather what we are shown on media tends to be driven by set agendas, the idea of profit and other vested interests. Media as the fourth pillar of democracy becomes central in the creation of an accessible and egalitarian public sphere. However the current media trends seem to be jeopardizing the ideals of a strong democracy.

We are not just confined by print sources for information. Rather we inhabit a multimedia age where people receive information from strong and powerful audio-visual imagery and multiple media formats [1]. The role of broadcasting, narrowcasting and the emergent information and communication technologies in disseminating information, ideas and values and organizing, influencing and shaping people's opinion cannot be undermined. Raymond William argued that democracy cannot be a one-way process and that multi-directional and open communications system is essential to democracy [2].

Media outlets are fundamental in shaping discussions and there by shaping democracy. But as stated earlier, we live in a democracy where mass media messages are mediated. It therefore becomes extremely important for the common man to understand the patterns of ownership and control of media outlets and inquire into what is left out or marginalized. Media democratization can only occur when people demystify the original structure, functions and operations of the media. This requires critical media literacy on part of the audience or the common man to understand the different shades of media organizations which are governed by the logic of profit accumulation.

\section{Objectives of the Study}

Mass media and media technologies pervade every aspect of our lives. The ever-increasing presence of media in our daily routines and lifestyles is quite evident from the practices we engage in since we wake up in the morning till the end of the day as we lull ourselves to deep slumber. With the all-encompassing presence of media technologies, it becomes imperative to judge the credibility of information being made available to us by various media outlets and make informed decisions and judgments based on the same. Thus it is one thing to consume media messages and another to critically analyze those messages and the factors that influence such messages. We live in a democracy where everything is mediated. Media messages and representations also play a crucial role in moulding public opinion and shaping a democracy.

This working paper is therefore an attempt:

- To analyze and draw from secondary literature the need and importance of critical media literacy in a mediated democracy

*Corresponding author: Sayanika Dutta, Centre for Mass Communication and Journalism, Cotton University, Guwahati, India, Tel: 0361273 3530; E-mail: sayanikadutta@gmail.com

Received January 24, 2018; Accepted July 27, 2018; Published August 03, 2018

Citation: Dutta S (2018) Critical Media Literacy in a Mediated Democracy. J Mass Communicat Journalism 8: 377. doi: 10.4172/2165-7912.1000377

Copyright: (c) 2018 Dutta S. This is an open-access article distributed under the terms of the Creative Commons Attribution License, which permits unrestricted use, distribution, and reproduction in any medium, provided the original author and source are credited. 
- To study people's perception and understanding about how the media works and their idea about factors like ownership, control, operation and functions of the media.

\section{Methodology}

This working paper is a qualitative study that draws heavily from the available secondary literature on critical media literacy and corelates its importance in a democratic set up. As an extension to the study, a preliminary study was done by personally interviewing four people of different backgrounds and qualifications. Due to paucity of time, the selection of the sample for the qualitative interview was very limited and based on convenience and the minimum criteria set for selection of the sample was their exposure to mass media in varying degrees i.e., light to heavy exposure to mass media. Open-ended and unstructured questions were posed to the interviewees to gather their views, ideas and perceptions on the topic.

\section{Understanding media literacy}

The concept of literacy entails the ability to comprehend and use messages that are written or printed symbols such as letters. Media literacy is something broader than that [3]. As documented by researchers, literacy has evolved historically from classic literacy to audiovisual literacy to digital literacy or information literacy and recently to new media literacy [4]. The concept of media literacy has a long past and has been there since the early days of print literacy [5]. A relatively new topic, the body of literature about media literacy is a large complex patchwork of ideas [6].

While several attempts have been made to obtain a concise definition of media literacy, in 1992, the "National Leadership Conference on Media Literacy" convention made an attempt to construct a single and concise definition of media literacy as "the ability to access, analyze, evaluate and communicate messages in a variety of forms" [7]. This by far remains the most widely agreed-upon definition of media literacy.

Media literacy broadly refers to the ability to access, analyze, evaluate and create media/content. These four components together compose a skills-based approach to media literacy. Each of the components is interrelated and offers support to other components in a non-linear process [5]. The Commission of the European Communities defines media literacy as ability to access the media, to understand and to critically evaluate different aspects of the media and media contents and to create communications in a variety of contexts. In the online context, the Commission defines media literacy for online as empowering users with tools to critically assess online content, extending digital creativity and production skills, ensuring that the benefits of the information society can be enjoyed by one and all including those who are disadvantaged due to limited resources or education, age, gender, ethnicity, people with disabilities as well as those living in less favored areas and raising awareness about how search engines work and learning how to use search engine effectively.

As Potter [5] points out, there are three key issues that confront scholars who consider the idea of media literacy. Firstly, what do media entail in 'media literacy', secondly, what do we mean by literacy and lastly, what should be the purpose of media literacy. The definition advocated by the National Leadership Conference on Media Literacy convention in 1992 however has one problem. As Tyner [8] points out that this definition often results in media literacy being confused with other literacies such as information literacy, visual literacy, technology literacy and computer literacy [9]. In terms of media literacy, it becomes essential to clarify which media we mean. While different scholars have focused on different mediums, Luke and others seem to suggest that media literacy could serve as an umbrella definition [9]. Infact, in the last decade or so, the convergence across mass mediums have rendered the distinctions between different mass mediums as unimportant compared to the similarities [10]. Therefore, there is a growing awareness that media literacy should be concerned with all forms of media. Addressing the second issue by what do we mean by media literacy, scholars have highlighted a variety of positions concerning the skills that are important and the set of knowledge that contribute to media literacy [6]. Critical thinking remains the most frequently mentioned skill as far as media literacy is concerned. Thirdly, the purpose of media literacy is to empower individuals by giving them more control over how the media messages affect them.

Scholars worldwide accept the following six foundation principles surrounding the concept of literacy and for teaching people literacy skills [3].

- Media Materials are constructed: what we see or read on media is not pure reality. It is rather a construction or a human creation that presents a kind of script about the culture.

- Media materials are created and distributed within a commercial environment: When we look at media materials we need to look at factors such surround and affect the people who are involved in creating and releasing the media materials. Mass media materials are produced by organisations that exist in a commercial setting and thereby these factors affect the final media products.

- Media materials are created and distributed within a political environment: The term 'political environment' refers to a variety of activities that affect the functioning of the media such as government regulations on mass media, court decisions, struggle by various interest groups to change what media do. This political environment deeply influences the media content itself thereby meaning that ideas in media have political implications and that they are ideological.

- Mass media present their ideas within primary genres of entertainment, news, information, education and advertising: This primarily means that every mass medium has its own codes and conventions and its own way of presenting cultural reality. A news report for a newspaper would differ from that of a television news channel.

- People are active recipients of media messages: The process of meaning making entails interaction between the reader and the materials. The social importance of mass media cannot be undermined and it can safely be said that a large section of the society see mass media as having cultural importance for the society as a whole.

- Media representation play a role in the way society understands its reality: Whatever the mass media representations are, people may either like what they see or complain about it. Either way, media representations play an important role in how people understand and perceive the reality.

Potter [6] has identified four common themes where there is general agreement across the writings about media literacy. First, the mass media have the potential to exert potentially negative effects on individuals. Second, the purpose of media literacy is to enable people gain greater control in one's life particularly from the constant influence of mass media. Third, media literacy can and must be developed and 
that no one is born media literate. And fourth, media literacy is multidimensional. Increasing one's media literacy requires development along several different dimensions: cognitive, emotional, aesthetic and moral.

\section{Need for critical media literacy in a democracy}

The word 'democracy' was conceptualized by the Greeks who were the first known people to take this idea of collective decision making and turn it into a system of government. In Greek, 'demos' means people and 'krates' means rule and democracy thereby meaning 'rule by the people'. In contrast to other forms of government, in a democracy people can exercise more control over the way they are governed [11]. In modern societies, what we see is representative democracies whereby people elect their representatives to make decisions on their behalf. As Fraley [2] rightly points out conversation, argument, debate and deliberation are all forms of interaction that remain central to a flourishing democracy. At times, these forms of interactions may lead to conflict which again is vital for a democracy to grow and mature. Communication is an important aspect of society that plays an important role in reinvigorating a participatory democracy which is accessible and responsive to any or all citizens. Media is one of the key mediums of communication in a democracy that provides a platform for debates, discussions and decision making.

However expecting the media to be completely objective and neutral would be a farce. Media industries work as per their own agendas. Propounded by Maxwell McCombs and Donald Shaw in 1972, the Agenda-setting theory states that the media sets the public agenda by telling people what to think about. The theory which is applicable to the news media propounds that in choosing and displaying news, broadcasters, editors and staff play an important role in shaping the political reality. Television news channels' increasing use of hashtags on pertinent issues carries the expressive character in a carefully constructed political discourse. News channels have their own agendas when it comes to creating hashtags.

Considering media's role in creating an accessible and egalitarian public sphere in a democracy and weighing the fact that media have their own set agendas, it becomes essential for the common man to be judgmental about the roles and functions of media. This is where the importance of critical media literacy in a democratic set up comes into play. Downing states that uncritical acceptance of media codes that claim to be objective actually hinders and cause blockages to public expression. These blockages hinder the development of a strong democracy.

There are three existing approaches to media education. One is the protectionist approach which aims at protecting people against the dangers of media manipulation and addiction. This approach posits media audiences as passive victims. The second approach is media arts education where students are taught to value the aesthetic qualities of media while using their creativity for self-expression through creating art and media. The third approach can be found in the media literacy movement which has made inroads into educational institutions and attempts to develop competencies to access, analyze, evaluate and communicate in different forms of media [1].

Kellner and Share [1] however propose a type of critical media literacy that includes aspects of the three models discussed above but at the same time focuses on critique and analyzing the politics of representation with regards to race, class, gender and sexuality, incorporating alternative media production and expanding textual analysis that includes the issues of social context, control and pleasure. The author write that in the context of a developing country like India, media literacy would entail critical skills to evaluate the role of media in a developing democratic society.

The author explains the need for critical media analysis by using the metaphor of an iceberg. He states that many educators guide their students only to analyze the obvious and overt tip of the iceberg that is visible to everyone. However the problem is that the vast bulk of media representations which are not visible are the intellectual, historical and analytical base. Without understanding this base, media analysis runs the risk of becoming superficial or mechanical.

Critical media literacy is concerned with developing skills that will enhance democratization and civic participation. It enables people to use media as instruments of communication and social change, both elements being an essential part of democracy.

Media literacy is critical as it instills the two important skills of critical thinking and self-expression and enables citizens to contribute to public discourse and make informed political and voting decisions. Critical media literacy teaches students not just to learn from media, but also to resist media manipulation, use media materials in constructive ways, develop skills that create good citizens and become active participants in social life [12].

Nayak [13] states that in a country like India with over 1.2 billion people, it is just not enough to say that media strengthens democracy and acts a voice of the voiceless. A critical assessment of media in India is crucial and media literacy tends to promote it. Media literacy promotes dialogue among various sections of people which is crucial for democracy to survive. Media literates can play an effective role in scrutinizing issues highlighted by the media, resolving issues within and outside the border and will be the vanguard of polity solution seekers of conflicts. Media literacy will pose a challenge and threat to the existing intellectual class which thrive on discourses that are far from being real and dish out solutions to societal problems that are mostly impractical. According to Nayak, media literacy can facilitate common man's understanding of the world that is vital for grassroots democracy.

\section{Discussion}

As an extension to the study, a small sample based on convenience was chosen for a qualitative study. Four people from different backgrounds, qualifications (one graduate, two post-graduates and one doctorate degree holders) and age groups (20 years-35 years) were chosen for personal interview. The sample was selected based on their exposure to mass media in varying degrees i.e., light to heavy exposure to mass media. Open-ended and unstructured questions were posed to the interviewees to gather their views, ideas and perceptions on influence of mass media in their lives, mass media's influence in shaping their opinions and world views, idea about how the media works, factors influencing the selection of particular media, idea about media objectivity, awareness about ownership pattern of the media they prefer, credibility of media content and being media critical.

Here's a brief discussion on the findings of the study.

\section{Influence of mass media in one's life}

The selection of the sample was done based on one criteria i.e., exposure to mass media. All the interviewees were exposed to media or relied on mass media in their daily lives in varying degrees. On being asked about how influential mass media is in their lives, some of the responses were as follows: 


\section{R1: It influences me a lot}

\section{R2: very much}

R3: somewhat, I rely on media for all the latest news and updates.

This hints at the fact that mass media does have a profound influence on one's life. As one of the respondents (R1) put it like this "It influences me a lot because I indulge myself in getting news and information related to the state and country through the media.... Sometimes the opinions put forth by the media matters to get the correct information". Another respondent (R2) replied to the influence of mass media as follows, "Very much because mass media drag our attention into (to) certain things and then we express our reactions on that particular matter". However, another respondent (R4) who was the most qualified of the lot and who seemed to have a heavy exposure to mass media said, "Mass media is significant in my life, but can't say it is influential".

From the opinions garnered, it could be said that people look up to media as a platform for debates and discussions based on which people give their reactions. Media is thus influential to some as it aides in decision making on issues that are pertinent and important. But at the same time, more well-read users of the mass media may not allow such media influences in their lives.

\section{Opinions about the world shaped by the mass media}

The common thread in the responses to this question was that everybody agreed to have set their opinions about the world based on mass media. Some of the responses garnered from the respondents were as follows:

\section{R1: "Yes, sometimes it basically depends on the topic"}

R2: "Some of the national and international media is influential, but not the regional media of Assam"

R3: "I don't get much influenced by the regional news media, but national media does influence me to a great extent"

R4: "Mass media definitely shapes my opinions about the world, but it is not based on one report, or one newspaper or one channel. It is the multiplicity of views that I gather, based on which I shape my opinions around an issue".

\section{Idea about how the media works}

Two of the respondents (R2 and R4) who agreed having heavy exposure to mass media answered in affirmative that they do have proper idea about how the media works. They could elaborate on the concept of profits, TRPs, circulation, ownership and other factors that influenced the functioning of the media. Although one respondent (R1) said that he understood how the media worked, he could not elaborate it further. The youngest respondent (R3) said that he did have much idea on how the media worked. It is seen that age factor, too, played an important role on users understanding of the mass media.

\section{Reasons for preferring one media over the other}

Respondents were asked as to what influenced their selection of one particular mass media over another. To this one respondent (R1) replied, "It depends upon the news, its presentation and quality". On being further asked as a follow up to the answer if it was the strong presentation that convinces him to select the media, the answer was a bold "Yes". Another respondent (R3) replied that it was clarity of presentation and simplicity of language that made him choose a medium over another. On being nudged further if the presentation style influenced him to believe the news, he replied, "Yes, if a piece of news is presented well, I tend to believe it is true". Style of presentation, thus, affected the believability of news. The respondent (R2) with heavy exposure to media however had a different opinion. He said, "I select a medium on the basis of reliability and accuracy of information and data". Another respondent (R4) stated it her selection of one media over another depended on "reasoning" and "background". While for the respondents with light exposure to media, television weighed over print media, the one with a heavy exposure to media gave equal preference to television and print for news, information and updates.

\section{Idea about ownership patterns of media}

Although all the four respondents answered in affirmative that they do have an idea about the ownership patterns of the media they watch or read, R3 could not elaborate on it on being asked. Two of the respondents with heavy exposure to mass media could, however, elaborate well on the issue. One of them (R2) made the following statement, "Yes, I often notice that media outlets owned by politicians and industrialists give more emphasis on highlighting owner's interests or achievements. So ownership patterns do affect the objectivity of media presentations".

\section{Presentation of views in media and its influence}

Two of the respondents (R1 and R3) agreed that the style and way of presentation did influence their thinking. R1 opined, "It does influence my opinion and thinking, especially topics on which I have less or no idea". R3 said, "On important topics, I look up to views forwarded in media to shape my own views and opinions".

However, respondents with heavy exposure to media and falling in an age category above 30 years opined, "The amount of influence is dependent on the presenter and the presentation of the issue" (R2). "After understanding the system how mass media works, the presentation of views does not influence me much" (R4).

\section{Being media critical}

On being questioned whether the respondents were media critical, there were some similarities in the responses.

R1: "Sometimes. It depends on the news. I believe that the news that is shown or presented may not be authentic, so I pay attention to different sources of news".

R2: "Sometimes, especially since I am aware that ownership patterns and owner's interest oriented news may drive a media outlet, I am pushed to become critical at times".

R3: "Yes, at times. Sometimes a small issue is blown out of proportion making me skeptical about its truthfulness".

\section{R4: "I am critical about media more often than not".}

This hints at people being media skeptical, even those with little or no knowledge of how the much operates and despite agreeing that media does influence them in a big way.

\section{Conclusion}

From the discussion above, one thing is clear that the mass media does play a significant role in our lives, also to the extent of being influential. The three important findings of the interviews are as follows:

1. An avid user of mass media had more control over what he/she 
watched, read and believed to be true in contrary to those with light exposure to mass media.

2. People with a better understanding of the working of the media were more resistant to media messages than those with limited understanding.

3. People today are media skeptical; Even those with little or no knowledge of how the much operates and despite agreeing that media does influence them in a big way are skeptical of the functioning of media.

Our opinions about the world are definitely a reflection of how media portrays or presents that issue and how we dissect the media deliberations to form our own opinions. Critical media literacy therefore holds significance as it constitutes a critique of mainstream approaches to literacy and a political project for democratic social change. It enables the common man to question media messages - why the message was sent and where it came from. The Secondary Education Commission of 1952 constituted by the Govt. of India articulated a vision of democracy. According to the Commission, a democratic citizen should have the understanding "to sift truth from falsehood, facts from propaganda and to reject the dangerous appeal of fanaticism and prejudice" (as cited in Silverblatt, Nagaraj, Kundu and Yadav). This is where an understanding of the media fits into the vision. Critical media literacy can make people reflect on key issues from different perspectives rather than accepting the media codes as they are framed and highlighted. It will only be befitting for democracies like India to pay more attention to the concept of critical media literacy and finding out ways to inculcate the ideas of critical thinking and analysis among people, more so among the children and the youth from an early age. The earlier they understand the importance of critical media literacy, more informed they will be of the issues around them thereby enhancing better and wider participation and thereby benefitting democracy at large.

\section{References}

1. Kellner D, Share J (2007) Critical Media Literacy, Democracy, and the Reconstruction of Education. In Media Literacy: A reader 3-23.

2. Fraley $T$ (2004) Mediated Communication, Democracy \& the Public Sphere: Critical media consciousness within progressive social movements.

3. Turow J (2009) Understanding Mass Media and the Importance of Media Literacy.

4. Jing WU, Wang Yu-mei (2011) Unpacking New Media Literacy. 9: 84-88.

5. Livingstone S (2005) Media Literacy- challenges ahead. LSE Research Online

6. Potter WJ (2010) The State of Media Literacy. Journal of Broadcasting and Electronic Media 54: 675-696.

7. Aufderheide P (1993) Media Literacy: A Report of the National Leadership Conference on Media Literacy. Communications and society.

8. Tyner KR (1998) Literacy in a digital world: teaching and learning in the age of information.

9. Schwarz G (2005) Overview: What is Media Literacy, Who Cares and Why? Wiley Online Library 104: 5-17.

10. Jenkins H (2006) Convergence culture: Where old and new media collide. New York Univ Press.

11. Woolf A (2005) Democracy(JN). WI: World Almanac Library.

12. Kellner D (2002) New technologies/new literacies: Restructuring education for a new millennium. London: Sage.

13. Nayak A (2014) Dialectical dimensions of media literacy discourse and socia dynamics in India. 